\title{
Erratum to: Adrenal cortex expression quantitative trait loci in a German Holstein $\times$ Charolais cross
}

Bodo Brand ${ }^{1,2 \dagger}$, Markus O. Scheinhardt ${ }^{3 \dagger}$, Juliane Friedrich ${ }^{4}$, Daisy Zimmer ${ }^{4}$, Norbert Reinsch ${ }^{5}$, Siriluck Ponsuksili ${ }^{1}$, Manfred Schwerin ${ }^{1,4}$ and Andreas Ziegler ${ }^{3,6,7^{*}}$

\section{Erratum}

Unfortunately, after publication of this article [1], it was noticed that an error in the PDF to an equation was introduced during the production process. On page 8 of the PDF, the equation reads:

$$
y_{i}=s_{j}+\beta x_{i}+\mathbb{S} \mid\left(a_{i f}+a_{i m}\right)+\varepsilon_{i}
$$

The equation should have read:

$$
y_{i}=s_{j}+\beta x_{i}+\frac{1}{2}\left(a_{i f}+a_{i m}\right)+e_{i}
$$

The original article has been updated to correct this error.

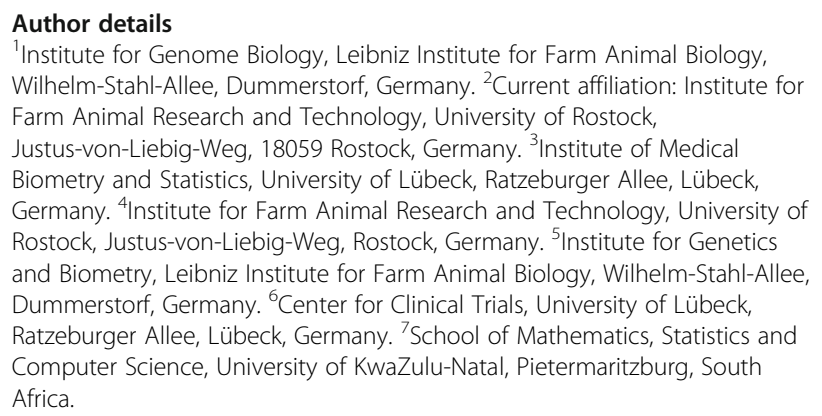

Received: 24 October 2016 Accepted: 24 October 2016

Published online: 30 November 2016

\section{Reference}

1. Bodo B, Scheinhardt MO, Juliane F, Daisy Z, Norbert R, Siriluck P, Manfred S,

Andreas Z. Adrenal cortex expression quantitative trait loci in a German Holstein

× Charolais cross. BMC Genetics. 2016;17:135. doi:10.1186/s12863-016-0442-x.

\footnotetext{
* Correspondence: ziegler@imbs.uni-luebeck.de

${ }^{\dagger}$ Equal contributors

3. Institute of Medical Biometry and Statistics, University of Lübeck,

Ratzeburger Allee, Lübeck, Germany

${ }^{6}$ Center for Clinical Trials, University of Lübeck, Ratzeburger Allee, Lübeck, Germany
} 